\title{
REPRESENTATIONS OF REALITY IN THE DEMARCATION ZONE BETWEEN REASON AND SENSATION IN ENGLISH AND BULGARIAN LANGUAGE ADVERTISING DISCOURSE
}

\author{
Rumyana Todorova*
}

\begin{abstract}
The paper deals with different representations of reality in the demarcation zone between reason and sensation in English and Bulgarian language advertising discourse. On the one hand, there exists an explicit requirement for advertising agents to describe the object of attention in a way which is nearest to the truth and the real world. On the other hand, text producers have to use enticing and sensational verbal and nonverbal means of expressing information so that they can sell not only the product but the life styles they are trying to impose on their target audiences. So, the strategies and techniques vary with various advertisements promoting goods and services even by the same company. The intermingling of knowledge and distortion of reality or irreality with the hope that ignorance or lack of knowledge on part of text receivers would help 'trick' them one way or another is shown in examples of English and Bulgarian language ads. The texts are structured in such a way that they can provoke consumers' dreams, illusions, fantasies and imagination for better feelings and emotions as well as pleasure and satisfaction bordering with perfect bliss.
\end{abstract}

Key words: reality, reason, sensation, demarcation zone, advertising discourse

\section{Introduction}

Advertising discourse contains information presented in most cases in an unusual and at times even strange manner which provides a lot of food for thought together with pleasure and satisfaction and last but not least provoking consumers' imagination and sensation. It is also expected for ads to reproduce 'the real thing' (see Wernick, 1994, p. 31) so that target audiences could be aware of the benefits of the products and services offered, though as Wernick asked: "If Coke is the real thing then what is real?" (ibid.). This statement means that reality in ads can have different faces depending on different factors. Some of them can be social and cultural, national or global, but others are definitely related to consumers' personal likes and dislikes, beliefs and prejudices, as well as ways of viewing and accepting the world around them and on a larger scale. These multiple representations can have a number of interpretations and probability predictions as the centre of orientation is not always the same for

* Professor PhD at Shumen University, Department of English Studies, Shumen, Bulgaria, e-mail: r.todorova@shu.bg. 
text producers and text receivers. There are cases, however, which challenge our imagination in more than one direction and it is us who decide which of the multifarious versions of reality would take us to our dreams and illusions and would satisfy and flatter our ego. It is a fact that advertisements represent reality in a sensational and provocative rather than in a reasonable and sensible way but it is also true that they also have an impact on reality even though we as text receivers are unwilling to admit it.

\section{Previous research in the field}

There is some research on representations of reality as well as on the use of imagination in various types of text. One of them is Wernick's treatment of reality connected with ideology (not in the political sense of the word) ${ }^{*}$ and symbolic expression of information (see Wernick, 1994). Todorova's book Strategies in the World of Advertising (2001) touches briefly upon this issue as regards the interrelation between enjoyment (as suggested by Lacan) and the pleasure principle (das Lustprinzip introduced by Freud) as opposed to reality bordering with the serious or as Freud calls it the reality principle (see Freud, 1985). In the book, reality in advertising discourse is presented through different values such as family, health, ecology, animal protection, the human ego, etc. expressed by a number of strategies advertising agents apply for the fulfillment of their aims.

Musolff and Zinken (2009) discuss the role of discourse for metaphorical meaning and understanding in cases of constructing various social realities. In their case reality is presented through the prism of metaphoric usages which can either coincide or be different in different cultures. As regards nonverbal representations of reality text recipients should apply a lot of imagination related to the use of multimodal metaphors and this fact is exploited by Forceville and Urios-Aparisi (2009) as well as by Kövecses (2010).

Various researchers elaborate on the issue of imagination and its interrelation with reality having to do with reason and sensation bordering with feelings, emotions, illusions and dreams. Thus, for example, Grady (2007) investigates the nonverbal occurrence of metaphors, while Fauconnier and Turner (2002) discuss their multimodality. Johnson (1990, p. xxxvi), however, treats imagination as "a creative capacity to reorder representations and to generate novel structures".

In respect to imagination and its relation to reality and knowledge, Einstein (n.d.) dwells upon the fact that "imagination is more important than knowledge"

\footnotetext{
* E.g. English Oxford Living Dictionaries provide the following definitions of ideology which suit the ads' purposes perfectly well: 'the set of beliefs characteristic of a social group or individual'; also, 'visionary speculation, especially of an unrealistic or idealistic nature'.
} 
and also that "knowledge is limited to what we know and understand, while imagination embraces the entire world". Charlie Galichibi (2015, URL) has come to the conclusion that imagination and knowledge are complementary because of their dynamic nature. Imagination is also the trick used "to satisfy our needs" and "to distract us from realities we would rather avoid" (ibid.). All this is true and can also be applied to advertising discourse where manipulation, knowledge and reason, creativity, imagination and sensation play the leading role for a successful advertising text.

Todorova (2018, pp. 297-302) has done a similar small-scale research in the respective field in a paper titled "Knowledge, Reality and Imagination in Advertising Discourse" where she shows that if text receivers are either ignorant or unaware of certain things related to the advertised object of attention, they would take the presented facts at face value and at the same time enjoy the information in the way it appears.

\subsection{Research Questions}

The present case study aims at showing how imagination and reality are exploited for achieving a greater effect related to the product in question on target audiences. In some cases what helps in depicting the narrative are parallel realities. In others, it is quite difficult to notice the demarcation line between imagination and reality. In still other cases, imagination is based on a different construal of reality or rather of an invented, created or distorted one and although text receivers are well aware of it they like it that way as they can start dreaming and imagining in the direction of their own construed reality-to-be until the point of buying the object of desire when everything can be broken down to lots of pieces of disillusionment or often times shattering dream-come-true stories, at least to a certain extent.

\section{Methods}

The methods used for the analysis of advertisements as regards the mentioned issues are Critical Discourse Analysis (CDA) and cognitive linguistics approaches which help interpreting the exploitation of imagination and sensation as a way of expressing various representations of our life and reality in the verbal and the nonverbal components of the ad narratives. Various cultural factors and social practices are also taken into account, if present and where needed.

\section{Data Analysis}

As the paper is part of a bigger study which focuses on the presented issues in commercials and billboards as well as in printed advertisements of different 
products, the analysis elaborates on the ways some of these issues are exploited.

Advertising, as part of the mass media, reflects in one way or another and at the same time creates various versions of reality. Therefore, it is of particular interest to see how different cultures use and employ their versions of reality in the analysed ads which are just some samples from the corpus.

In the excerpted sources, the commercials are more dynamic and the shots follow in quick succession, which allows audiences to use their imagination more often than not as it is difficult at times to follow the narrative and they have to fill in the missing gaps in a way they like or make up the stories according to their own knowledge, views and perspectives about the world they live in and at large. On the contrary, the print ads rely on the simultaneous multimodal exhibition of information, thus leaving the reader to decode the intended information by making references to the verbal and the nonverbal components of the respective ads. In some cases the recipients' interpretations can be contrary to what advertising agents have planned and projected. In principle, the role of copywriters is not to represent reality as it is, as this kind of depicting it would be boring and uninteresting especially in such types of text. The idea behind the message is as Alberto Giacometti, a famous Swiss artist, has stated about the impact of art on people, "The object of art is not to reproduce reality, but to create a reality of the same intensity" (n.d.). So, advertising agents usually recontextualize universal human experiences and give them some plausible relevance to the object of attention, which means that they do not directly replicate reality but give it a certain twist that will serve their aims and will bring about pleasurable feelings in potential buyers. In connection to advertising and how it provokes people's imagination, another quote of Giacometti's about art is also true about the way we perceive the world, "When you look at art made by other people, you see what you need to see in it" (ibid.). So, once again everything depends on consumers' views, prejudices and beliefs as well as on their needs and demands on which they start building their imaginary stories. Imagination, however, is definitely connected with personal experience. In this respect, advertising agents provoke it in their own ways. As Edward Hopper reveals he "realizes that what he is making is not a depiction of reality, it is a depiction of HIS reality. The way he feels about a subject is inherent in the way he renders it" (Popular Posts, 2018).

As regards the interconnection between imagination and knowledge, Albert Einstein (2018) states, "I'm enough of an artist to draw freely on my imagination, which I think is more important than knowledge. Knowledge is limited. Imagination encircles the world". In principle, imagination feeds on knowledge and reality due to sense and reason. 
In commercials imagination triggers a number of anticipatory mechanisms and audiences start making hypotheses and presuppositions of what to expect as the narrative goes on.

Such narratives which are quite sensational and provoke audiences' imagination are the Peugeot ones broadcast on Bulgarian TV. They are based on different real life situations but the unexpectedness and even strangeness of the presentation of information makes them rather intriguing and challenging. This trick helps advertisers reinvent the brand image so that it becomes even more memorable and desirable. The information about the respective car does not matter that much as it can be found anywhere else. What is of importance is related to the drives and the associations the narrative provokes in every person, undoubtedly connected with their imaginations, desires and illusions. These can be social status, identity and self-esteem, confidence in society or at least in the community one lives and works.

Thus, one of the Peugeot 208 commercials reads in the following way*:

'There is no more icing left'

or in another commercial:

'More icing/ there is none left/ There are no fruits' (in a restaurant's kitchen; false statement as one can see in the nonverbal component that there is plenty of everything and cannot guess what the person's intentions are).

'If you lend me your car I'll go and get some' (the presupposition can be as I do not have one and it will be much quicker that way; the idea, however, is that it is worth driving such a car at least for a moment and that it is a real treat).

In a while, the dialogue goes on as follows:

'What happened?'

and the reaction is:

'Everything is shipshape'.

In the abovementioned texts a lot is left to the text receivers' imagination and a lot of anticipatory mechanisms are at play.

In another one of the same brand, though, the information is more or less predictable in the Bulgarian culture and real life situation. It may not be the case in other cultures and circumstances:

'Look. Some cronies are loitering around your car. If you don't move it, you'll be sorry'. (The idea is again for his boss to give him the keys for the car and let him do the job because he likes driving this make of car even for a little while).

\footnotetext{
* The author has presented the translated versions of the Bulgarian ads in order to facilitate processing ease. Translation: author's.
} 
In billboards the time for using our imagination and predictions is quite short as we can almost immediately find out what the information is all about. And yet, the way the message is presented provokes our fantasies and we start dreaming. In some cases it can be daydreaming but still it has to do with the workings of the human mind in the direction of something desired and something that will never be fulfilled, if we do not buy and avail ourselves of the advertised product. Thus, in the following billboards about Kaufland products in Bulgaria there are quite a lot of things to wish for rather than the products themselves:

'The emperor would like a generous treat

With quality products from Kaufland'

'The queen is looking forward to/expecting a king's feast

With quality products from Kaufland

Nice week'

'The prince is looking forward to/expecting a king's feast

With quality products from Kaufland'

Though these are not repetitive experiences and are imaginary in themselves as they are based on the fairy tales we know dating back to our childhood, they have to do with the so called learned knowledge. Not that kings, queens and emperors do not exist in real life, but they are far away from our own reality and present-day situation in Bulgaria and only the knowledge and the memory we have of them makes us accept such information unproblematically. This kind of reproducing a version of reality is called rote replication of reality and has to do with "learning something in order to be able to repeat it from memory rather than to understand it" (Cambridge Dictionary, 2018). In the abovementioned ads it does not mean that we do not understand them. But it seems that the situation is too far away from the Bulgarian reality. In this case, it turns out that the messages about the products Kaufland offers are presented in a somehow pseudo real way but this does not hinder comprehension as "our perceptions cannot always be equated with reality" (see Applequist, 2013, p. 903). It does not take addressees a lot of time to grasp the information either and it is connected with space construal as text receivers do not normally stop in front of billboards for a longer time. The presented situations are constructed around two lexicothematic fields which are interrelated. One of them consists of king, queen, prince and in another ad of theirs there is also a princess. The other one is related to treat, feast and products. So, 'high quality' is the uniting element and the interrelation between the two as the semantic features of the entities from the first field are "high esteem" and "royalty", while in the second one treat has to do with "a special and enjoyable occasion or experience" and feast - with "enjoyable thing", "something that is very enjoyable to see, hear, experience" (Cambridge Dictionary, 2018). There is an expression in English "treat sb like royalty" which validates the aforementioned statement and makes it possible 
for the fields to intermingle. The positive characteristics of both entities are transferred to products. From then on, until some products from Kaufland are bought potential customers can start imagining a number of things pretending for a moment at least that they are in the king's, queen's or prince's shoes and dreaming that they are having a 'generous treat' or a 'feast' with Kaufland goods. In this way, the unexpected, surprising and challenging beginning of the texts attracts the audience's attention and the copywriter's aim is easily achieved. TV commercials about Kaufland products express the same idea but this time the characters are played by small children which allows for the subconscious connection of the narrative with fairy tales which children love to watch and listen to. This does not mean that these commercials target kids; they address mainly and mostly their parents who themselves had once been kids and what is more, they love their children and satisfy their preferences in any possible way. So, in every kid playing the part of either a prince or a princess families see their own little treasures. Thus, imagination coupled with enjoyment is in full force again. The transfer of messages and meanings is fulfilled with the mixing of entities from two domains as people mentally make the connection between time (past and present) and space (the present environment) (see Radden, 2011). In these particular texts the borderline is between the existence of kings, queens, princesses and princes in an invented reality or world of fairy tales and the present. As for space dimensions, the narrative appears in a presentday situation and environment. In the Bulgarian situation this presentation of reality in the ad is invented or pseudo real, but in another culture, say British, Swedish, Danish or Belgian, this narrative corresponds perfectly well to one of the messages. What matters, though, is the provider's intention to 'upgrade' the level of service, obviously with lots of delicacies, i.e. the queen's and the prince's treats will be like the king's feasts - lavish and generous.

In the following billboards of Kaufland's in Bulgaria there are again one sentence texts which leave text recipients make probability predictions in any way they like or can depending on their background knowledge. They can imagine or create various versions of (invented) reality based on this statement:

'Your daughter is with a broken heart. Again.

Whatever happens.'

'My mother-in-law is coming for a visit. But is fasting.

Whatever happens.'

These two texts are more predictable as they presuppose the answer and anybody can make up a story based on the reported news but definitely connecting it with Kaufland and the products they offer. In these cases, advertising agents rely on the sensation provoked by the unexpectedness of the information. Yet, the information makes sense but the viewers are tickled and left to decide what narrative to contrive on their own. These are open-ended billboards letting 
text receivers choose their products according to the respective situations and according to their own tastes. Some interpretations can be: In the first message, mothers (or parents) will compensate for their daughter's bad mood with some food from Kaufland as their child loves it. In the second message, some women having mothers-in-law may react negatively and go for the products their husbands' mothers do not like or cannot eat just then. The sensation is there, anyway, and the connection with reality is plausible and possible. As people like sensations and news having negative nuances, they will like the ad, as some of the understatements can be: 'It serves her right' or 'So, what?'.

In the last two cases, the stories are constructed on the basis of familiar cognitive and social models of the world and as such they are easily recognizable and identifiable. The interpretations, though, can be different for each text receiver depending on their background, culture and community setting, personal experiences, views, prejudices, beliefs and points of orientation.

As for English language commercials, some of my favourites are the ones about Nespresso featuring George Clooney in which there is always something unexpected, sensational and at times unreal or even absurd. There is a lot left to addressees to presuppose, make (wild) guesses or assumptions and inferences and apply a lot of anticipatory mechanisms and hypotheses. However, all of these would have been much easier to solve with the help of any of the search methods for decoding information*, if they were print advertisements. With commercials, because of the dynamism in the succession of shots and the progression of the narrative, which is very dynamic in the mentioned ones, there is no time for retrieval of information at all. So, target audiences have to use their imagination in any way they like, which makes the story even more interesting and intriguing for them as they themselves get involved in it and become part of it. Sensation is there but in the long run they have to have some reason while making each move as the plot is often unpredictable. What they should definitely possess in some cases is some previous information about some details utilised in the information.

Last but not least, I will provide only one of the many examples in this respect with one of Nespresso's latest commercials from April 27, 2017. Viewers should have some knowledge of the films some shots of which are intricately interwoven in the commercial but with George Clooney "montaged" in them. So, we should ask the question: Is this the augmented** reality which is the hype nowadays? Anyway, what is inevitable is the so called complementarity of imagination and knowledge. If we want our imagined mental spaces to take the right direction

\footnotetext{
* For search methods see de Beaugrande, R., \& Dressler, W. (1981). Introduction to text linguistics. London, New York: Longman; see also Todorova, R. (2015). Strategii v sveta na reklamata. Shumen: Konstantin Preslavsky Publishing House.

** For a definition of 'augmented reality' see Rouse (n.d.).
} 
we should have some prior knowledge of what is happening in the world around us and at large. In this case, it turns out that the travel scenes used in the commercial are from several classic films: The Muppet Movie; Easy Rider; Smokey and the Bandit; Planes, Trains and Automobiles; and Seabiscuit. The narrative includes some shots along Clooney's trip from a place where there are only ordinary coffee machines to Nespresso Boutique \& Café in Beverly Hills. The reason for this long trip is a phone call by Andy Garcia who is drinking Nespresso in a nice environment and starts teasing Clooney with the idea of having one with him by saying:

'Hello from paradise. How is it going? Oh, it's a perfect Nespresso morning, George? Hold on a second' (he is sipping his coffee making a noise of pleasure and satisfaction over mobile phone)

The place Andy Garcia is at is somewhere in the tropics with hot weather, while George Clooney is obviously shooting a film at a place with awful weather conditions - chilly and rainy. The trip George Clooney undertakes is imaginary and actually non-existent, but the place he gets to is real, not invented. Once again we get to Wernick's question: 'If Coke is the real thing then what is real?' (see Wernick, 1994, p. 31). The answer is definitely, at least for the situation in the ad:

\section{'Nespresso. What else?'}

The (il)logicality is kept till the end when first the barista in the coffee shop asks him an ambiguous question:

'How far would you go? (after a pause) For a coffee?'

And then, Andy Garcia comes up with a phone call from the place Clooney originally was. One can see that he has obviously decided to take a Nespresso machine to George:

'Hey, George! Where are you? I brought you a Nespresso.'

Thus, once again, reason, reality, sensation and enjoyment go hand in hand in these types of text but in most cases the demarcation zone is hard to define.

\section{Results and Key Findings}

The analysis confirmed the fact that there are a couple of social-cultural as well as cognitive factors that play an important role in decoding the way reality is presented in advertisements irrespective of the products offered. In each case, different manipulative strategies are applied connected with previous knowledge and personal experience, reliance on sensation, yet bordering with reason at least to a certain extent. Imagination plays a dual role first, because it is used by text producers the way they feel the plot of the ad, and second, because text receivers will use their own imaginative inclinations. Whether these two types of imagination overlap, coincide or take different strands is a question which 
remains unanswered because of personal experiences, likes and/or dislikes and of the various ways of addressees' view of the world.

\section{Conclusion}

In general, advertising agents have some ideas expressed in the presentation of the promoted object of attention but as people are different and as they accept the world in a different way their interpretations of the virtual or augmented reality and imaginations will be different. However, what matters most is the fulfillment of the pleasure principle which triggers sensations, dreams and illusions while receiving information from advertisements loaded with plenty of distorted and dream-to-be realities which may eventually 'come true', if potential consumers buy the product or avail ourselves of the services offered. The disparity between the reality we live in and the created reality in advertising discourse is what does the trick in the manipulation of target audiences.

\section{Implications}

The implications for future research in this field can be to extend the analysis to a number of ads showing one and the same brands by different companies and use informants so that we study the way they decode the respective ads and use their imagination based on the multimodal representation of invented 'real life' stories and narratives while making their purchasing decisions. Augmented reality in advertising discourse is also a state-of-the-art way of using various means for depicting information in the digital era, which is definitely something to dwell and elaborate on.

\section{References:}

Applequist, J. (2013). Book review. In A. Hestroni (ed.), International Journal of Communication, 7 (2013). Advertising and reality: A global study of representation and content. 903-905.

Beaugrande, R. de, \& Dressler, W. (1981). Introduction to Text Linguistics. London, New York: Longman.

Donna, K. (2018). Making a movie in the yard...and beyond! Gravity Was Everywhere Back Then. Retrieved from http://gravitywaseverywherebackthen.blogspot. com/2013/07/if-you-could-say-it-in-words-there_13.html.

Einstein, A. (2018). In RMIT Launchpad. Choose a Career You Love. Retrieved from https://www.rmitlaunchpad.com/stories/212-albert-einstein.

Einstein, A. (n.d.). https://www.goodreads.com/quotes/556030-imagination-is-moreimportant-than-knowledge-for-knowledge-is-limited.

Forceville, C., \& Urios-Aparisi, E. (eds.) (2009). Multimodal metaphor. Berlin: Mouton de Gruyter. 
Freud, S. (1985). Art and literature. vol. 14. Dickinson A. (ed.). London: Penguin.

Freud, L. (n.d.). Lucian Freud quotes. Brainy Quotes. Retrieved from https://www. brainyquote.com/quotes/lucian_freud_305836.

Galichibi, Ch. (2015, March 3). Is imagination more important than knowledge? Retrieved from https://www.linkedin.com/pulse/imagination-more-important-thanknowledge-ein stein-charlie-gilichibi.

Giacometti, A. (n.d.). The object of art is not ... In AZ Quotes. Retrieved from http:// www.azquotes.com/quote/535146.

Hu, Ch. Z. (2015, April 21). Art as a different reality. The Harvard Crimson. Retrieved from https://www.thecrimson.com/column/artistic-matchmaker/article/2015/4/21/ artist-matchmaker-art-as-a-different-reality/

Ideology (2018). In English Oxford Living Dictionaries. Retrieved from https:// en.oxforddictionaries.com/definition/ideology.

Johnson, M. (1990). The Body in the mind. The bodily basis of meaning, imagination and reason. Chicago and London: The University of Chicago Press.

Kövecses, Z. (2010). Metaphor: A practical introduction. New York: Oxford University Press.

Lacan, J. (1994). The four fundamental concepts of psycho-analysis. Ed. Jacques-Alain Miller. Trans. by A. Sheridan. London: Penguin.

Musolff, A., \& Zinken, J. (2009). Metaphor and discourse. New York: Palgrave Macmillan.

Nespresso Commercial (2017, April 27). In YouTube. Retrieved from https:/www. youtube.com/watch?v=AReiAzfVcEY.

Radden, G. (2011). Spatial time in the West and the East. In Brdar, M., Omazic, M., Takac, V., Gradecak-Erdeljic, T., \& Buljan G. (eds.), Space and time in language. Frankfurt: Peter Lang.

Rote (2018). In Cambridge Dictionary. Retrieved from https://dictionary.cambridge. org/ dictionary/english/rote.

Rouse, M. (n.d.). Augmented reality (AR). In WhatIs.Com. Retrieved from https:// whatis. techtarget.com/definition/augmented-reality-AR.

Todorova, R. (2001). Strategii v sveta na reklamata. Shumen: Konstantin Preslavsky Publishing House.

Todorova, R. (2015). Insights in Text Linguistics. From Theory to Practice. Shumen: Konstantin Preslavsky Publishing House.

Todorova, R. (2018). Knowledge, reality and imagination in advertising discourse. In Knowledge. International Journal, Vol. 22.1. Vrnjacka Banja, Serbia: Institute of Knowledge Management. 297-302.

Treat (2018). In Cambridge Dictionary. Retrieved from https://dictionary.cambridge. org/ dictionary/english/treat.

Wernick, A. (1994). Promotional culture. Advertising, ideology and symbolic expression. London, Newbury Park, New Delhi: Sage Publications. 